\title{
Las nuevas formas laborales en la economía del precariado El caso de los repartidores a domicilio de las plataformas Rappi, Uber Eats y Glovo
}

\author{
Joselyn Carrión Chulluncuy
}

Universidad Nacional Mayor de San Marcos, Lima, Perú

joselyn.carrion @ unmsm.edu.pe

\author{
Rubén Ticona Fernández Dávila \\ Universidad Ricardo Palma, Lima, Perú \\ ruben.ticona @urp.edu.pe
}

\begin{abstract}
RESUMEN
La economía neoliberal en su proceso de expansión y continua capacidad de reinvención se ha adaptado a los nuevos contextos de crisis económicas, y ha generado relaciones socioeconómicas bajo nuevas formas laborales y mecanismos de trabajo. Es así como desde la última década han surgido masivamente trabajos precarios en la denominada economía colaborativa que reproducen y extienden la continua informalización y precariedad del empleo en la sociedad peruana, ahora envuelta en el discurso del emprendedurismo. El objetivo del artículo es analizar las nuevas formas laborales emergentes en la economía del precariado, a partir del estudio de casos de los repartidores a domicilio de las plataformas Rappi, Uber Eats y Glovo. La metodología utilizada ha sido cualitativa, se realizó 12 entrevistas a profundidad, el trabajo de campo se aplicó entre el 2018-2019 en Lima Metropolitana.
\end{abstract}

Palabras clave: Neoliberalismo, economía del precariado, economía colaborativa, empleo juvenil, emprendedurismo

\section{The new labor systems in the economy of the precariat. The case of deliverymen through Rappi, Uber Eats and Glovo platforms}

\begin{abstract}
The neoliberal economy in its process of expansion and continuous capacity of reinvention has been adapted to the new contexts of crisis and has generated socioeconomics relations under new forms of labor relations and mechanisms of work. This is how since the last decade new forms of independent work have massively emerged, precarious jobs in the so called collaborative economy that reproduce and extend the continuous informalization and precariousness of employment in Peruvian society, now involved in the entrepreneurship speech. The aim is to analyze the new emerging labor forms in the precariat economy, all of this on the base of a case study of the delivery men of the Rappi, Uber eats and Glovo platforms. The methodology used has been qualitative, 12 in-depth interviews were conducted, the fieldwork was carried out between 2018-2019 in Lima Metropolitana.
\end{abstract}

KeYwords: Neoliberalism, the economy of the precariat, youth employment, informality, entrepreneurship 


\section{Economía del precariado}

Hoy las sociedades son testigos de profundas transformaciones económicas y sociolaborales que ocurren a su interior y que se caracterizan por las incertidumbres que generan en vastos sectores poblacionales. Algunos reconocidos sociólogos han definido los tiempos contemporáneos como la sociedad del riesgo, la cual ha nacido del quiebre de la sociedad productiva de clase: «la producción social de riqueza va acompañada sistemáticamente por la producción social de riesgos» (Beck, 2013, p. 29) El riesgo como anticipación a la catástrofe. de un futuro abierto, lleno de inseguridades y obstáculos. $\mathrm{O}$ la propuesta de Bauman (2004) que la caracteriza como la sociedad liquida. en donde las relaciones laborales rompen con los patrones de la era industrial como la jerarquía, los horarios fijos, la estabilidad laboral. En suma, se ha transformado la esencia del trabajo como bien común, a la esencia del trabajo individual el futuro como proyecto se ha desvanecido. Una modernidad (líquida) responsable del crecimiento constante de temor en las sociedades industriales. Para Castel (2015) esta modernidad ha generado un vaciamiento de las estructuras económico-políticas, relegando al Estado a una posición subordinada con respecto al mercado y las demandas del ciudadano, produciendo una inseguridad social como la nueva condición de nuestra época.

Es claro que se ha instalado en la sociedad un nuevo problema con respecto a la inseguridad; un aumento de la incertidumbre y una especie de malestar frente al porvenir laboral que hoy se agudiza inmerso en una convergencia de crisis: económica, social, política y ecológica.

En este marco histórico hay en curso una reestructuración y nuevas relaciones en el mundo del trabajo, los cuales hay que entenderlos también a la luz de los cambios ocurrido en el patrón de acumulación capitalista y de sus políticas económicas. En tal sentido, una breve contextualización nos permitirá dar cuenta de los procesos de transformación operados en el modelo de desarrollo que ha impactado en el ámbito del empleo y las remuneraciones al trabajo.

El anterior modelo de acumulación, con su apuesta en el mercado interno como eje de crecimiento económico, fue característico de América Latina hasta la década del 70, De un modelo de desarrollo centrado en el mercado interno se cambió progresivamente hacia un modelo basado en el mercado externo. Este nuevo patrón de acumulación basado en la apertura comercial, el estímulo a las exportaciones, una mínima intervención del Estado en la vida económica, y en general el desmantelamiento de la reglamentación de los mercados, han sido decisivos para la reconfiguración del desarrollo de la economía y la capacidad de generación de empleo y de sus ulteriores consecuencias en las relaciones laborales.

Paralelamente, en el mundo se producía una transformación en la relación entre Estado y mercado, que reconfiguraba la naturaleza del Estado social, el cual era asediado 
desde diversos frentes políticos, económicos e ideológicos. Como sostiene (Navarro, 2002), la crisis tiene que ver con el acoso permanente al Estado de bienestar, garante de los derechos sociales y laborales, como consecuencia de un neoliberalismo imperante, que a través de sus políticas se enfocó en desregular los mercados financieros y la desigualdad de la renta, en lugar de mejorar las servicios sociales para el acceso a una mejor calidad de vida como: la educación, la sanidad, servicios de ayuda, creación de trabajo, pensiones los transportes, las telecomunicaciones, etc.

La socióloga, Sassen (2015), explica este conjunto de hechos como consecuencia de las expulsiones que el propio sistema capitalista produce, sostiene la tesis de que la economía global en su proceso de expansión produce cada vez mayor desigualdad y desempleo, como una condición del sistema, y que estas dos últimas décadas se ha presenciado las expulsiones que no son parte de una lógica espontanea o casual sino que es producido por un conjunto de instituciones, políticas e instrumentos, que producen personas y empresas que son expulsadas, desalojadas y erradicadas de los órdenes sociales y económicos de nuestro tiempo con consecuencias devastadoras para las sociedades.

Asedio que ha sido continuo y que se ha agudizado durante el último periodo de la gran recesión como consecuencias de la crisis del 2008, y que ha traído consigo el proceso desmantelamiento de derechos como lo plantea Navarro (2015) quien sostiene que se han aplicado políticas públicas que han dañado intensamente la calidad democrática y el bienestar de la mayoría de las poblaciones, puesto que, las respuesta a las últimas crisis económicas producidas han sido fundamentalmente políticas de austeridad del gasto social y a reformas laborales, que solo han favorecido a los propietarios del gran capital, generando un enorme crecimiento de las desigualdades. Para Standing, (2017) Se trata del colapso del capitalismo neoliberal y que ha traído el aumento de la desigualdad. En donde se mezcla un sistema rentista opresivo y la existencia de una nueva clase social sin posibilidad de mejora, desprotegida, el precariado.

En este contexto histórico el empleo ha sido precarizado profundamente durante las últimas tres décadas generando procesos de empobrecimiento y desigualdad social inéditos, que ampliamente ha sido documentado por las investigaciones de Pikketty (2014) y Stiglitz (2015) y otros autores.

Ya no se trata solo de un síntoma de nuestra contemporaneidad sino la condición de la época signada por la inseguridad social permanente, al respecto Castel (2013) sostiene que el Estado social está siendo erosionado inevitablemente y con él, las organizaciones colectivas protectoras, relaciones de trabajo y la protección social. La sociedad salarial que prometía la reducción de las desigualdades está derrumbándose. «Se sabe que desde hace un cuarto de siglo ese edificio de protecciones montado en el marco de la sociedad salarial se ha fisurado, y que sigue resquebrajándose bajo los golpes propinados por la hegemonía creciente del mercado». (p.117) 
En importante anotar aquí la necesaria relación que plantea Castel, entre la reducción de las protecciones sociales y la mayor ampliación de la desigualdad social, puesto que analizar las inequidades de América Latina, considerada la región más desigual del mundo, está vinculada estrechamente a las dinámicas de su mercado de trabajo.

Como sostiene Rodríguez (2010) en América Latina, la persistencia de la desigualdad está relacionada con el mercado de trabajo, no solo por el desempleo estructural, sino que este ha sido agravado por la crisis económica mundial que comenzó en el año 2008 y que no solo ha aumentado el número de desempleados sino también de la informalidad y la disminución de empleos con protección social. De igual manera, De la Garza (2000) afirma que en América Latina hay una crisis del trabajo, pero es sobre todo una crisis de precarización de las actividades.

Respecto a este último aspecto, sobre la disminución del empleo de calidad como el problema fundamental, coinciden con Standing (2014) «El dilema no es que el desempleo aumente, sino casi lo contrario, el «menor crecimiento de los empleos»-la extensión de los empleos de baja productividad con bajos salarios y casi sin beneficios salariales» p. 10

En este sentido, se puede entender la extensión cada vez mayor en diversas regiones del mundo de una nueva condición laboral marcada por su continua precarización laboral de los trabajadores en todos los campos, a esta masa laboral creciente sin protección social alguna, Standing (2013) la ha denominado Precariado ${ }^{1}$.

Una nueva clase social emergente que tiene como una de sus principales características la inseguridad permanente y no coyuntural y que esta sigue creciendo en función del avance del capitalismo neoliberal. Que, entre sus múltiples características, se encuentran: el sometimiento a jornadas laborales extensas; la obligación de atender a cualquier demanda sea en cualquier momento y lugar, una incertidumbre acerca de las oportunidades de mejora que lo obliga a asumir diversos trabajos. Trabajar bajo presión es la constante con horarios extenuantes que lo imposibilita de descansar adecuadamente y de reducirle el tiempo para la vida familiar, comunitaria y política lo que se traduce en un bajo nivel de ciudadanía y el permanente debilitamiento de la democracia. Precariedad que en muchos casos para los trabajadores es la única opción, por lo tanto, le resulta deseable este tipo de empleo frente a la posibilidad de no tenerlo en un corto plazo si no se cumple con las demandas y exigencias laborales del empleador,

1 Standing (2014) Plantea tres rasgos distintivos para caracterizar a esta nueva clase social, el precariado tiene diferentes relaciones de producción el precariado tiene un empleo inseguro, inestable, cambiando rápidamente de un trabajo a otro, a menudo con contratos incompletos o forzados a puestos de trabajo negociados e intermediados mediante agencias o brokers. está sometido a lo que denomina precarización -se refiere más bien a una pérdida de control sobre el propio tiempo y sobre el desarrollo y uso de las capacidades propias. Unido a la escasez de la continuidad laboral, asimismo debe emplear mucho más recurso en trabajo no remunerado, «trabajo para buscar trabajo" Un segundo rasgo definitorio es que recibe casi todos sus ingresos en forma de salarios monetarios; sin embargo, no recibe la serie de beneficios no salariales de la empresa ni tampoco los beneficios regulados por las leyes del Estado. En tercer lugar, tienen menos derechos civiles, culturales, sociales, políticos y económicos. pp. 8-10 
que evidencian más una relación laboral caracterizada por una neoexplotación laboral del siglo XXI.

Realidad laboral que retrató y advirtió Forrester (1996) de un fenómeno que había estado pasando inadvertido en la sociedad, la extinción del trabajo y que, por primera vez en la historia, el conjunto de los seres humanos es cada vez menos necesario. «... hay algo peor que la explotación del hombre: la ausencia de explotación, que el conjunto de los seres humanos sea considerado superfluo y que cada uno de los que integra ese conjunto tiemble ante la perspectiva de no seguir siendo explotable...» Forrester, critica el aumento del trabajo precario, de los sistemas de flexibilización del trabajo, todo lo cual conduce a un incremento de la inseguridad para los trabajadores y para la sociedad.

Situación que se produjo paralelamente al recorte de derechos laborales, Standing (2013) indica que «por primera vez en la historia, los gobiernos están restringiendo los derechos a sus propios pueblos» (p. 13). Señala que un aspecto destacado de la flexibilidad del mercado laboral es que los riesgos y la inseguridad en el trabajo, así como su falta (desempleo), se transfieren a los propios trabajadores y a sus familias. Se hace creer que se trata de un problema que compete al sujeto abordar en forma individual. Instalándose en la sociedad de esta manera el discurso ideológico del «emprendedurismo», puesto que ya no es el problema estructural en la sociedad, no es más la responsabilidad del Estado o de la empresa de la falta del empleo o el subempleo, sino que es responsabilidad del propio individuo por no poder convertirse en un sujeto contratable por un mercado laboral, emprender aquí equivale convertirse en un producto que se ofrece a otros, los que ostentan capital, llamando su atención para que vean en tu persona un valor a explotar, a emplear.

Moruno (2015) sostiene que la devastadora crisis financiera desatada en 2008 ha multiplicado la presencia en nuestra sociedad de la figura del "emprendedor» ${ }^{2}$. Con el colapso del modelo laboral tradicional. «La crisis de hoy es la crisis de los 70, una crisis del modelo constitucional basado en una determinada organización del trabajo» (p. 149)

Este discurso del emprendedurismo no considera el contexto ni la desigualdad socioeconómica, ni el punto de partida de los sujetos, entre las múltiples causas. Los neoliberales asumen que el éxito o el fracaso en un entorno laboral, depende única y exclusivamente del esfuerzo de los trabajadores.

2 El modelo ideológico del emprendedor puesto de moda por la industria mediática y los gobiernos, sería en términos de Moruno (2015), «...la figura de proletario, un precariado a veces asalariado, a veces falso autónomo, a veces pequeño empresario, a veces sin papeles, donde en distinto grado, condición situación y descripción comparte la ausencia o erosión a todo derecho adquirido a toda garantía social... la explotación se presenta en todo lugar y en cualquier momento, donde la precariedad es la protagonista. El individuo se asume como un producto, que debe saber gestionar sus emociones, su forma de comunicar, de presentarse en la sociedad comuna mentalidad positiva, pues de ese gobierno de si mismo depende su empleabilidad y la posibilidad de aspirar a ser explotados laboralmente», En tal sentido, este individuo sería el responsable de alcanzar el éxito, pero si no lo logra él es responsable de su fracaso y en consecuencia de su pobreza. En suma, estamos frente un individuo esquizofrénico que persigue el mandato de éxito promovida por la sociedad del consumismo. 
Postura que ha sido desbaratada, por sus inconsistencias históricas, económicas y subjetivistas que evidencian un discurso sesgado, ya el economista Stiglitz (2015) pone en evidencia la mentira de la «meritocracia» y la teoría del «esfuerzo personal», señalando que el 90\% de los que nacen pobres mueren pobres por más esfuerzo o mérito que hagan, y del otro sector social sostiene que el $90 \%$ de los que nacen ricos mueren ricos, independientemente de que hagan.

Es importante anotar que el capitalismo contemporáneo en su continuo proceso de transformación, se reinventa tomando como referencia la propuesta teórica de Boltanski y Chiapello, (2018) quienes se apoyan en la concepción del capitalismo de Schumpeter, que consideró que el verdadero motor del desarrollo económico era la «destrucción creadora» por parte de los empresarios innovadores. Ambos autores sostienen que el capitalismo es profundamente revolucionario y dotado de una dinámica consistente en una continua transformación de sus modos de organización, de producción y comercialización, con una invención permanente de nuevos productos y servicios.

Tesis que también es retomada por Moruno (2015), para dar cuenta de la crisis como un proceso que se manifiesta en un doble movimiento, "primero como un proceso destituyente de lo construido que camina paralelamente a otro constituyente en términos de actualización del capitalismo» (p. 151)

Boltanski y Chiapello (2018) argumentan que si la explotación perdura es gracias precisamente a ese reinventarse bajo nuevas formas y modalidades de explotación que vive la fuerza de trabajo en el capitalismo conexionista, organizado en forma de red y que tiene en la noción de proyecto, la actividad organizada en proyectos que no distingue entre espacios/tiempos profesionales y espacios/tiempos personales. Así todas las dimensiones de la vida del sujeto se muestran empleables.

Aspectos nuevos del trabajo que también han sido ampliados a partir de las reflexiones que plantea Moruno (2018) quien afirma que el triunfo de la ideología neoliberal se explica en la medida en que "su presencia sea su ausencia». Puesto que no es solo un sistema de dominación, sino una forma de vida real, que adapta a los individuos a las necesidades del mercado. Sostiene que inclusive hasta nuestro tiempo propio queda como materia susceptible de ser tratada desde la óptica del mercado. En tal sentido, se ha conseguido que el trabajo sea parte de cada momento de nuestra vida, en gran medida a la mediación tecnológica, la celularización y la economía colaborativa, se trataría de «trabacaciones» ${ }^{3}$,

3 Término propio de Espańa, con el que se designa como las nuevas fórmulas de empleo han cambiado los periodos de vacaciones y los descansos. Ahora los profesionales deben gestionar su tiempo para resolver asuntos laborales en cualquier momento, formato que era más común entre los trabajadores independientes que operan por proyectos. Sin embargo, la digitalización ha hecho que diversas empresas empiecen a recurrir a estos modelos de forma cada vez más extendida. 
Moruno (2015) concluye que la extensión de la precariedad como condición existencial y la aparición de condiciones de servidumbre y de nuevas formas de explotación, como consecuencia, en parte, por la economía de las plataformas digitales y sustentado ideológicamente con el coaching y el discurso del emprendedor ha encapsulado al sujeto despojándole inclusive de su tiempo de descanso y de su propio yo.

Por lo tanto, se hace más necesario ahora la reconstrucción de un Estado social que resguarde a las personas de los avatares de la existencia misma (desempleo, vejez, enfermedad accidentes de trabajo y otros) y que según Castel (2012) (2015) esta protección social es necesaria porque permite la construcción de una sociedad de semejantes, una ciudadanía social donde nadie queda excluido porque cada uno dispone de los recursos y de los derechos necesarios para mantener relaciones de interdependencia y no solo de dependencia. En tal sentido, propone salvar el Estado social para luchar contra la inseguridad social, desarrollando y reconfigurando las protecciones sociales necesaria para sostener la democracia.

La aplicación del modelo neoliberal económico en el caso peruano impulsó un conjunto de políticas públicas cuyos únicos objetivos no solo fueron recortar derechos sino también facilitar una devaluación salarial profunda lo que generó también una reducción de los empleos poco cualificados, este nuevo escenario se vio agravado por el desmoronamiento de los servicios sociales, de modo que, a la par que se propagaba la precarización social simultáneamente se instaló una cultura de inseguridad y miedo ante la posibilidad de perder el empleo. Sus manifestaciones hasta la actualidad en términos sociales podrían ser resumido en la incapacidad de la economía peruana para generar empleos adecuados, lo que ha permitido una mayor proliferación de las actividades informales de muy pequeña escala, más cercanas a estrategias de sobrevivencias para la mera reproducción social que empresas emergentes y asimismo el surgimiento de la economía colaborativa envuelta del discurso del emprendedurismo.

\section{Emergencia de la economía colaborativa}

Las economías colaborativas, como nuevas formas laborales, responden al contexto de la economía neoliberal, que tuvo un primer auge en los países europeos y principalmente en Espańa, ya que por los ańos 60 y 70 se empezaron a ver algunas primeras prácticas de tipo colaborativa, las cuales consistían en hacer uso de algún bien de propiedad de otra persona y que, al no estar en valía, podía ser usado por otra que lo necesitase en el momento. Ya con el desarrollo de la ciencia y la renovación tecnológica en la era digital, se impulsaron fuertemente. En un primer momento, no buscó generar solo una rentabilidad, sino que buscó emplear, es decir poner en valor, el tiempo y los bienes disponibles, para su concesión temporal o en todo caso, para su uso compartido. Este nuevo 
entorno económico, social y político, que se configura desde inicios del siglo XXI, permitió un desarrollo más globalizado, en respuesta al sistema mundo, que favorecía una nueva economía y que hoy, tiene repercusiones graves en el aspecto social. Hay quienes afirman que estas prácticas responden a los inicios de la cuarta revolución industrial, la cual se caracteriza por la fusión de las tecnologías y medios; y que ocasionan que cada vez sea menor la línea divisoria entre el escenario de lo físico, lo digital y lo biológico ${ }^{4}$.

Pero fue la crisis económica del 2008 la que afectó gravemente el poder adquisitivo en los sectores mayoritarios de la población, generando nuevas condiciones para el desarrollo de estas nuevas economías de tipo colaborativa, que esta vez se presentaban dentro del mercado competitivo como una opción de consumo más económica y rentable; además que ofrecía un nuevo campo de empleo alternativo y opcional, que les permitía generar ingresos extras.

El Banco Interamericano para el Desarrollo (BID), menciona en un informe del 2016, que las economías colaborativas, son una muestra de lo que significa el desarrollo digital en la economía, que alcanzó popularidad en el 2010. El informe del BID coincide en señalar que las economías colaborativas surgieron por la creciente necesidad económica, el cual se dio a consecuencia de los niveles altos de desempleo y que, sumado a la existencia de recursos económicos infrautilizados (o dicho de otro modo, no aprovechados por sus dueños originales), hicieron más atractiva este tipo de economía colaborativa. Botsman (2013) (como se citó en BID 2016) menciona que la economía colaborativa se basa en la reinvención de lo que se consume, es decir, consumir otras cosas que el mercado tradicional no ofrece; y reinventa la forma en que se consume, es decir, consumir de un modo distinto.

Un punto importante por señalar y que en este informe se menciona también, es lo relacionado al contexto latinoamericano y el impacto de las economías colaborativas. Ya que, sin duda, y como parte del proceso de globalización, estas economías encontraron un contexto apto para su aceptación y desarrollo. Esto debido a la adopción de políticas económicas de corte neoliberal, ligadas a la apertura de mercados, la liberación fiscal e impuestos y que, sumado al impacto de la crisis económica capitalista, constituyeron los elementos para el desarrollo de este nuevo modelo.

\section{Las economías colaborativas, impacto y desarrollo}

El BID señala en su informe del 2016, que las economías colaborativas son una nueva modalidad de producción e intercambio de bienes y servicios que, apoyados por el desarrollo tecnológico, se da mediante el uso de plataformas digitales. Se puede seña-

4 Klaus Shwab, fundador y director ejecutivo del World Economic Forum, 2013. 
lar también que las economías colaborativas son un modelo de negocio, que se dan en plataformas on-line, el cual facilita la apertura de mercados para el ofrecimiento o adquisición temporal de mercancías o servicios. E identifica tres tipos de agentes que intervienen, los proveedores del servicio (ejemplo: repartidores), los consumidores y las plataformas, según lo señala la Comisión Europea en el 2016. Por su parte, el Comité Económico y Social Europeo, señaló en el mismo año que este tipo de economía es un modelo sostenible para el siglo XXI, ya que promueve valores como la cooperación y sobre todo, garantiza una solución viable a la crisis económica y financiera, pues facilita los intercambios BID (2016).

Otros estudios, como el de la Comisión Nacional de los Mercados y la Competencia (de España), describe que las economías colaborativas son una especie de catalizador de los problemas de coordinación entre oferta y demanda que se dan en el mercado, además se concibe que las economías colaborativas son un conjunto heterogéneo y con alta variabilidad en sus modos de producción y de consumo. En el 2014, un informe elaborado por NESTA5, Making sense of the collaborative economy, menciona que las economías colaborativas son una nueva forma de hacer negocios y que depende de algunas condiciones como el uso de internet, promueve interacciones significativas con base en la confianza y aprovecha recursos que no son usados adecuadamente. Como sostiene Gil García (2017) todos estos conceptos elaborados responden a distintas visiones con respecto a esta forma laboral, sin embargo, ninguna de ellas se refiere a los factores socioeconómicos que conlleva a la adopción de estas prácticas económicas, por lo que es importante señalar algunos factores. La primera de ellas referida a las posibilidades de acceso a este tipo de trabajo, los costos que genera el laborar mediante esta forma, los beneficios y la rentabilidad que se puede obtener. Todos estos factores dependerán de las condiciones socioeconómicas propias de la persona, tanto de quien hace el servicio como de aquel o aquella que usa el servicio.

En ese sentido, han surgido algunos debates que lidian con la idea de que estas nuevas formas laborales de tipo colaborativa son la oportunidad para el crecimiento personal y el ascenso económico, dentro de una lógica propia del discurso del emprendedurismo. Precisamente, los defensores de estas prácticas laborales apelan a las oportunidades que brinda este sistema para el aprovechamiento de los recursos disponibles y para la generación de riqueza, ya que se posibilita que la población pueda obtener ingresos extra, mediante el empleo de su tiempo libre y de la forma como mejor les parezca. Además que estas condiciones de trabajo permiten el abaratamiento de los precios para los consumidores. En respuesta a esta visión, surge una posición crítica que señala que estas formas de trabajo alternativo rompen con las lógicas del marcado tradicional y ejercen

5 Fundación internacional de innovación con sede en el Reino Unido, fundado por David Puttman, que busca «ayudar a las personas y a las organizaciones a convertir grandes ideas en una realidad», según lo describe la página: https://www.mejoracompetitiva.es/2013/06/nesta-un- motor-para-la-innovacion/ 
una competencia desleal, ya que se aprovechan de su no regulación y su permanencia dentro del campo de la economía informal. Pero surge también una crítica más fuerte y que apunta a excavar detrás de la imagen de «economía colaborativa», asumida como una estrategia de marketing, el cual señala que este tipo de economía es un sistema de precarización laboral que canaliza, de manera indirecta, los riesgos comerciales hacia los propios trabajadores, a quienes se les incorpora dentro de una renovada identidad de microemprendedores. (Kalamar, 2013)

Esta precariedad laboral, se puede entender mejor en el tipo de economía colaborativa de reparto a domicilio, mediante el uso de aplicativos móviles, ya que, en este modelo, se hace más clara la promoción de lógicas de trabajo autónomo y de tipo independiente, en donde las relaciones laborales no existen porque se asumen como innecesarias. Estas características ocasionan que se diluyan y se alteren las relaciones de empleo entre un trabajador y un empleador, desapareciendo con ello, los derechos que se sostienen en los vínculos contractuales, como beneficios laborales, seguros de vida o salud, indemnizaciones, el derecho a la sindicalización, entre otros. Lo que hace la economía colaborativa, en el ámbito social, es promover la idea de autonomía y denominar a los agentes prestadores del servicio como «colaboradores» y no trabajadores, con lo que se hace posible que se internalice en el trabajador, la idea de que no tiene ningún vínculo con la empresa y por tanto no pueden exigirle nada ni tampoco puede demandar nada. Estos "colaboradores», al no tener relación contractual con la empresa, pasan a desempeñar sus funciones como una forma de intermediación, haciendo llegar los servicios o bienes que ofrece la empresa a los usuarios que lo demanden. Es decir, estos "colaboradores» pasan a ocupar la posición de un «tercero», entregan los servicios que la empresa ofrece, pero sin ser parte orgánica o formal de la estructura de la empresa. La tercerización laboral, como modelo de precarización, es una característica de este tipo de economía colaborativa.

Otra característica por añadir a este tipo de economía colaborativa es la flexibilización laboral, la cual alude a la autonomía que el «colaborador» tiene para decidir cómo y cuándo realizar la entrega de los servicios o bienes; por lo que se dificulta la creación de vínculos estables y se reducen los costos o riesgos económicos que implicaría un contrato formal, como la alimentación o seguros. Además, que impide que se ejecuten cobros de impuestos, pues la residencia de la empresa no es fija y por lo general, su origen o su residencia se haya en otras localidades.

La situación de América Latina es también necesario señalarlo a media que estas economías de tipo colaborativa van abriéndose paso, en un contexto favorecido por la flexibilización de las políticas públicas, la apertura económica a mercados globales y a la reproducción social de una cultura del delivery, el cual se refiere a la incapacidad de las personas para hacer sus propios mandados, necesitando de un tercero para satisfacer esas necesidades (Correa, 2018, como se citó en Vallefin, 2018). Este modelo económi- 
co y de mercado, según la publicación del BID en el 2016, sería una oportunidad para integrar a la región al proceso de la Cuarta Revolución Industrial, pues favorecería a la inclusión social y promueve lógicas de trabajo de emprendimiento ${ }^{6}$. Sin embargo, hasta la actualidad, no se ha profundizado en un estudio sobre los impactos generados a partir del desarrollo de estas economías. Los estudios aplicados a la realidad de América Latina son estudios ajenos a la propia realidad, hecha desde una mirada ajena.

A continuación, señalamos que algunos estudios analizan las economías colaborativas como parte de un proceso económico más complejo, denominado, economía prosumidora. La economía prosumidora sería una nueva forma de producir, intercambiar y consumir bienes o servicios, que se ve respaldada en las nuevas tecnologías como el internet, los smartphones, las redes digitales, aplicaciones móviles y plataformas virtuales. Además, este tipo de economía hace posible que las diferencias que existen entre productores y consumidores se disuelvan y se configure a un sujeto prosumidor, quien es aquel que hace las funciones de producción y consumo al mismo tiempo.

Es decir, con mayor frecuencia el proceso de producir bienes se hace en espacios de consumo y el consumo se hace cada vez más productivo, Gil García (2017). Existen cinco tipos de economía prosumidora

Prosumición por datos: producción de Big Data; prosumición de contenidos: producción de contenidos digital en distintas formas de forma prosumidora (mensaje, audio, video); prosumición de servicios: formas de prosumición propias de la economía colaborativa; prosumición manufacturera: por ejemplo, las actividades prosumidoras que emplean impresoras 3D para producir; y prosumición energética: formas de producción energética eólica o solar bajo formas prosumidoras.

De estos tipos, enfatizaremos en la prosumisión de servicios, es decir, la economía colaborativa. En este tipo de prosumisión, los bienes y servicios ofertados ya no son producto del trabajo asalariado, sino que son resultado del trabajo independiente, en donde no se percibe un salario sino una rentabilidad. A este trabajo "independiente» se le va adjudicar el nombre de trabajo prosumidor, el cual se vale de la autonomía laboral. Según Gil García (2017) se puede diferenciar cuatro elementos que caracterizan el trabajo autónomo. 1. El tiempo y espacios de trabajo: Las diferencias entre el tiempo y espacio de trabajo y no-trabajo, se diluyen y el trabajo acapara todo el tiempo de la persona. Las personas usan aún sus tiempos «libres» para seguir produciendo y estos se vuelven espacios económicamente productivos. 2. Contenido del trabajo: El trabajo autónomo demanda que el trabajador ponga en práctica sus habilidades comunicativas que afiancen una mejor relación con los consumidores. El prosumidor debe hacer uso de ex-

6 Discutido en el Foro Económico Mundial celebrado en Suiza en el 2016. 
ternalidades que aseguren un mayor valor al bien ofrecido, como la forma en cómo se comunica, se relaciona o se expresa con el consumidor. Solo así se logrará que el servicio se concrete. 3. La retribución del trabajo: La remuneración que el trabajador prosumidor percibe depende ahora de la productividad, de la calidad del servicio prestado, es decir, ya no se remunera el trabajo realizado en sí, Por ello se señala que el trabajo prosumidor no es un trabajo asalariado, pero sí remunerado. Esto ocasiona que se ponga en debate y se anulen todos los beneficios y derechos que tiene el trabajador, siendo un riego real para este, pero algo insignificante para las empresas. 4. El trabajo se autoorganiza: El prosumidor es el encargado de iniciar y realizar el proceso productivo, mientras que las plataformas solo se dedican a captar y distribuir el reparto del bien.

Estas características propias de la economía prosumidora por servicios o economía colaborativa y su impacto en la dinámica laboral de la sociedad, dan muestra de cómo el neoliberalismo va siendo adaptado a las políticas estatales y cómo estas van más allá de lo económico e impactan fuertemente sobre los otros ámbitos de la vida social. La economía neoliberal se vuelve, a su vez, en una fuerte influencia que rige la vida.

Recordemos que el contexto de toda esta lógica nueva de mercado se inicia con una crisis, en donde el capitalismo, como una suerte de mantenerse vigente, se reinventó e impulsó el nacimiento de nuevas prácticas laborales, que permitiesen acoger a aquellos afectados, quienes perdieron empleos o que vieron reducido el nivel de su salario. Es entonces que estas economías se presentan como esa oportunidad de ingresos extras y como una forma de empleo novedoso. Surge a su vez, un nuevo mercado de consumo, en la que se pone en práctica estas economías colaborativas y las relaciones en torno a ellas. El convertirse en un nuevo medio de reproducción social distinta a la tradicional, hizo posible que se generen las condiciones para la construcción de una nueva subjetividad, autónoma e independiente, acorde a la lógica neoliberal.

Pero estas nuevas oportunidades que ofrece la economía colaborativa no están a disposición de toda persona, sino que dependen de las condiciones socioeconómicas. Las personas con aspiración a gozar y acceder a estas nuevas prácticas laborales no tienen la misma capacidad para acceder a sus beneficios; por lo que el ser aceptado como sujeto prosumidor significaría una forma de acceder a esos beneficios, generándose una reproducción social desigual. Gil García (2017) menciona la existencia de un tipo de capital prosumidor, que no sería otra cosa que el capital acumulado por el sujeto prosumidor como parte de las economías colaborativas y que van a regir o condicionar los beneficios o perjuicios alcanzados por el sujeto prosumidor

Este capital prosumidor puede ser de tipo económico, cultural, social, educativo, político, etc. y se divide en dos tipos, uno económico y otro humano. El primero reúne a todos los recursos materiales y técnicos, es decir, es capital económico expresado en bienes. El segundo tipo de capital reúne una serie de atributos del sujeto prosumidor, ya sea cultural, educativo, social, afectivo y otros. A su vez, estos dos tipos de capitales se 
dividen en necesarios y complementarios, que a continuación se detalla. 1. Capital económico necesario: expresada en la posesión de tecnología indispensable para el proceso económico colaborativo, el uso de smartphone, tablets, aplicaciones, plataformas y el acceso a internet, bicicletas o motocicletas (alquiladas). 2. Capital económico complementario: expresada en recursos materiales al que solo tienen acceso un grupo reducido de personas, ejemplo: viviendas, carros, motocicletas propias. 3. Capital humano necesario: se refiere a la capacidad e iniciativa que tiene el trabajador prosumidor para hacer más efectiva la entrega de los bienes y servicios; por ejemplo: el buen trato, valores, etc. 4. Capital humano complementario: es el conjunto de capital inmaterial, que ha sido adquirido por ubicarse en una posición socioeconómica más estable, este puede ser capital cultural, educativo, etc. el cual permitirá gestionar mejor la entrega del bien o servicio, empleando sus capacidades desarrolladas en otras formas de prosumisión. (Gil García, 2017).

Pero no toda persona que desea ser parte de esta economía colaborativa goza de los mismos beneficios o recursos (capitales). En ese sentido, hay quienes, al no contar con los capitales económicos ni humanos de tipo complementarios y solo concentran capitales de tipo necesario o básico, se ven en la obligación de ofrecer su trabajo y su tiempo (en mayores proporciones y en peores condiciones), con el fin de acceder a los «beneficios» que ofrecería la economía colaborativa. Se entiende, entonces, que la concentración de ciertos tipos de capitales determina el acceso de la población a la economía colaborativa. Ello evidencia que este modelo económico genera condiciones desiguales, de acuerdo a las características socioeconómicas. La población, en general, no cuenta con las mismas posibilidades de participación, siendo las actitudes y destrezas que desarrolla el trabajador prosumidor importantes para que pueda generar un mayor y diverso número de capitales. Este tipo de trabajo se configura como el único camino que tienen las personas que no disponen de capital económico ni humano suficientes, para poder generar un ingreso, pero en condiciones laborales precarias.

\section{Estudio de casos}

En el Perú aproximadamente desde el 2018 han ingresado al mercado y a la economía nacional estas formas de economía colaborativa expresadas en los repartos a domicilio mediante el uso de aplicativos móviles. Apoyados en la expansión de la tecnología y el boom de estos aplicativos, este tipo de servicio de entregas se ha extendido llegando a distritos "populares» como San Juan de Lurigancho, Manchay, Los Olivos o Comas, saliendo de esa zona de «confort» de los distritos como Miraflores o San Isidro. Empresas como Rappi, Glovo, Pedidos Ya o Uber Eats, (que acaba de retirarse del Perú como resultado de la crisis sanitaria), entre otras, han intentado generar un precedente con 
características no vistas antes en este territorio, validando prácticas precarias que ante el Estado pasa por "agua tibia» y está muy lejos de regularla.

Los servicios que prestan estas empresas no solo es el de reparto de bienes, como comida; hacen las veces de ejecutor de recados, entregando o llevando objetos o pertenencias de los usuarios a distintos puntos.

Para los fines de este artículo se presentan brevemente los casos de las empresas Glovo, Rappi y Uber Eats, los cuales nos permitirán ejemplificar las características y problemáticas señaladas.

\section{a) Rappi}

Esta es una plataforma de repartos a domicilios, fue fundado en agosto del 2015 por Simón Borrero, Felipe Villamarín y Sebastián Mejía, en Bogotá, Colombia. Se inició como un experimento y se presentó como la primera opción de pedidos por aplicativo, con la opción de realizar los pagos en efectivo. Su fundador Simón Borrero, señala que la plataforma cumple la función de ser un "centro comercial virtual», que reúne todos los bienes disponibles en una zona determinada para su entrega a domicilio. Es más, él mismo señala que "En Rappi ayudamos a las personas a ahorrar tiempo y a dedicarlo en actividades que le generan mayor valor en un mundo cada vez más evolucionado» (En portal web).

Esta plataforma tiene por objetivo el exhibir los distintos productos y servicios disponibles para servir de referencia a los consumidores, además pretende facilitar la conexión entre los consumidores y repartidores en medio de un vínculo comercial. Así mismo, el diseńo de la empresa, mediante el uso de una plataforma virtual, permite que se realicen compras y ventas sin necesidad de que intervenga en el proceso los operadores de la plataforma. Largacha, \& Tatis, (2017). Uno de los atractivos que ofrece esta plataforma es su servicio de Rappi Cash, mediante el cual, un usuario puede solicitar que se le lleve dinero en efectivo hasta el lugar en donde esté (Perez, 2016). Un elemento importante para el funcionamiento de la plataforma son los repartidores, quienes adquieren el apelativo de rappitenderos, y trabajan bajo la figura de microempresarios, quienes no están sujetos a contrato, están libres de impuestos y laboran bajo la informalidad. Estos rappitenderos ganan un porcentaje por pedido, estableciendo ellos mismos un contacto directo con el negocio que elabora el bien. Mientras que las plataformas, solo cumplen el papel de seguimiento y monitoreo de la actividad de entregas, mediante el sistema GPS. (Pérez, 2016)

Rappi llega al Perú en los últimos meses del 2018 y sumó a sus filas cientos de repartidores, convirtiéndolos así en "rappitenderos», esto gracias a las novedades que ofrecía, entre las que destacaba el uso de un medio de transporte ligero y más accesible, la bicicleta; además que ofrecía mayores ganancias a comparación de las otras empresas. 


\section{b) Uber Eats}

Esta es una plataforma de pedidos a domicilios y que entró al mercado Latinoamericano, con Colombia, en diciembre del 2016. Años antes, en el 2014, se lanzó en Los Ángeles, un piloto y al año siguiente, en el 2015, se lanza al mercado la aplicación, en la ciudad de Toronto. Actualmente, esta plataforma se ha extendido por varias ciudades de Latinoamérica. Largacha \& Tatis, (2017). Uber Eats es una aplicación independiente de Uber, y permite hacer pedidos de comida a domicilio. Esta plataforma mantiene una lista amplia de restaurantes que permite al usuario, elegir comida variada.

Esta plataforma llega al Perú en el año 2018, bajo el mando de Joana Garay y teniendo como aliados a unos trecientos restaurantes y a mil repartidores. Uber Eats tiene presencia en países como Colombia, Chile, México, Costa Rica y otros más. Inga (2018).

\section{c) Glovo}

Es una plataforma de mensajería rápida y de reparto a domicilio, mediante el uso de un sitio web o el uso de una aplicación móvil. Las entregas se realizan en un aproximado de 30 minutos. Al igual que Rappi, esta plataforma tiene una amplia variedad de servicios. Este nace en España en el año 2015, bajo el amparo de su creador, Óscar Pierre Miquel. Más tarde llega a Italia, mediante la adquisición de la empresa Foodinho, una empresa dedicada al reparto de comida; y en el 2016 llegó a Francia. Hipola (2017). En diciembre del 2017 llega al Perú, ofreciendo sus servicios solo en Lima, con un costo de cinco soles (S/. 5.00) por pedido (Inga, 2018). En ese mismo año, pero un mes antes, llegó a Chile, concentrando entonces ciento cincuenta mil usuarios activos y unos mil conductores; $y$ en sus primeros años ha llegado a facturar unos diecisiete millones de dólares (\$/. 17.000 000).

Según el portal web América Retail en Sudamérica ha llegado a casi todos los países. A nivel general, Glovo funciona mediante el uso de un aplicativo móvil, en donde se puede encontrar una amplia carta de ofertas, desde flores, regalos, hasta comida, también incluye una opción extra con el rótulo de "lo que sea», con el cual el usuario puede atreverse a pedir que le lleven las llaves. Al seleccionar una opción, se muestra una lista de establecimientos, así como también el promedio de tiempo en que demoraría en llegar el pedido. El aplicativo está diseñado para él o la usuaria pueda elegir un pedido con las características exactas que desea. Los repartidores a cargo del servicio adquieren el apelativo de Glovers, quienes trabajan de manera «libre». ( Hípola, 2017).

A partir de estas aproximaciones generales, sobre el proceso de constitución de las empresas repartidoras, desde su fundación hasta su llegada al Perú, podemos referirnos ahora a casos concretos, cómo es que se asumen estas nuevas propuestas de generación de ingresos, su efecto en lo social y en lo personal. A partir de la descripción de la relación entre los repartidores, empresa y usuarios; y a partir de la descripción etnográfica 
en tres entrevistas hechas a dos repartidores. La interacción inicia al momento en que un usuario o una usuaria, solicita un servicio o un bien mediante el aplicativo móvil, este pedido, inmediatamente es recepcionado por un repartidor más cercano al área, quien traslada el bien desde el lugar en donde se encuentra (restaurant, oficina, domicilio, etc.) hasta el lugar en donde se encuentra el usuario o hasta el lugar asignado por el usuario. La interacción finaliza con el pago por el servicio, el cual se hace en efectivo o por medio del aplicativo.

A continuación, se presentan los relatos de los casos de tres repartidores de estas empresas líneas arriba mencionadas.

\section{a) «Luis»}

Luis, como lo llamaremos en este análisis, es un repartidor de la empresa Rappi, tiene treinta y tres ańos y es de Lima. Vive en el Rímac, junto a su familia, su esposa y sus cuatro hijos, todos menores de edad. Él trabaja en Miraflores, menciona que decidió postular, se inscribió, lo aceptaron, pasó una capacitación de un día y ya con ello se hizo repartidor. La decisión por trabajar en Rappi lo hizo por los beneficios que tiene ahí, la libertad que tiene, la flexibilidad en los horarios y el monto que gana, fueron suficientes como para que empiece a trabajar ahí. Antes ya había trabajado por una empresa de reparto, Glovo, pero al salir Rappi se hizo más atractivo y por ello decidió irse para ahí. También había laborado para la empresa Claro por mucho tiempo, en el área de ventas de celular, en el que pudo aprender el trato al cliente y ello ahora le sirve para poder trabajar y lidiar con cualquier inconveniente que surja. Ya que, debido a la poca comunicación que tiene con la empresa, dificulta la resolución de problemas que se puedan presentar. Como él explica, el soporte de Rappi es operado desde Colombia y al estar en una realidad distinta, hace imposible que puedan entender las condiciones y dificultades que significa laborar en una realidad como Lima.

Luis, trabaja en moto y ello le permite movilizarse por varios distritos cercanos a Miraflores, como San Isidro, Surco, Surquillo y otros. La ganancia que percibe se debe a dos montos, uno por el kilometraje que corre por cada pedido, el cual tiene una base de S/. 1.20; y por pedido tiene unos S/. 2.25. Él empieza a trabajar desde las diez de la mańana y se queda hasta las diez u once de la noche. En un día puede llegar a tener unos ciento veinte o ciento cincuenta soles. Juan comenta que en Rappi, por el momento está bien, le permite poder salir a pasear con su familia cuando quiere y hacer los gastos que surjan sin remordimientos. A diferencia de las otras empresas en donde piden algunos requisitos que hacen más dificultoso poder trabajar, por ejemplo, el pagar un porcentaje a la SUNAT y estar declarando mensualmente, es algo que limita el trabajo. Él tiene un seguro médico, ESSALUD, con el que trabaja con más tranquilidad, además la moto cuenta con SOAT, en caso de cualquier accidente. En un buen día puede 
ganar unos doscientos cincuenta soles y en un día bajo llega a cincuenta soles, como mínimo. De esa forma, puede llegar a ganar al mes unos dos mil quinientos soles. Luis, además ha llegado a hacer compañeros, con los que conversa esporádicamente, pero ello no significa una relación más significativa. Pese a ello, él cree que, con el tiempo, los repartidores llegarán a sindicalizarse, pero en respuesta a la demanda que tendrá la empresa con el tiempo. Reconoce también que por el tipo de trabajo que tiene está propenso a la delincuencia, sin embargo, es algo común a toda la sociedad. Cree además que las autoridades deberían mejorar esta situación, pero de manera apropiada, sin estar limitando los derechos de las personas.

\section{«María»}

María es una joven venezolana de veinte años, que tiene en el Perú dos años. Ella vive en La Molina, junto a sus padres y su hermano y tiene unas semanas trabajando en Rappi. Ella hace los repartos usando una bicicleta que es suya y recorre el distrito de Miraflores. Antes de entrar a Rappi ella estuvo trabajando de cocinera y mesera, algo que hasta ahora realiza a la par de este trabajo de reparto. Por lo general ella considera que tiene varias ventajas trabajando en Rappi, pero cree que, al no ser un trabajo fijo o seguro, puede significar un problema. Rappi, según explica ella, te permite hacer de todo, pedir servicios de comida, así como pedir una llave. La bicicleta le resulta cómoda sin embargo significa un peligro real, aunque Miraflores se presenta como un distrito amigable, aun así, se encuentra propensa a sufrir algún daño en cualquier momento. Ella logra a recibir como ganancia unos tres soles por pedido. Al día puede hacerse uno ocho pedidos en promedio, trabajando unas ocho horas.

Ella reconoce que la relación que mantiene con la empresa en informal, es más, reconoce que se encuentra laborando en una condición de informalidad; y que el hecho de no tener una rigurosidad al momento de contratar, permite que puedan entrar a laborar cualquier persona.

Ella al día puede llegar a ganar unos sesenta soles, algo que depende de la capacidad física que se tenga, mientras que en un día bajo solo llega a alcanzar la suma de diez soles, en promedio. Esto lo logra hacer trabajando de diez de la mañana hasta las seis de la tarde. El trabajo de rappitendero parece ser exclusivo para hombres ya que muy poco se ve a mujeres sobre una moto o bicicleta, María menciona que hay una proporción de $80 \%$ hombres contra unos $20 \%$ mujeres.

\section{«Juan»}

Juan es un joven de 32 años, que vive en casa de sus padres, en el distrito de San Juan de Miraflores. Es soltero y es padre de una menor. Tiene un negocio propio de tallado en 
madera, habilitando un espacio de la casa de sus padres. Pero que, debido a las necesidades económicas, decide por abrirse paso en busca de otra fuente de ingresos. Si bien aún mantiene su negocio propio, hoy es parte de la flota de Uber Eats, empresa norteamericana que desde mediados del año pasado empezó a operar en el Perú. El postular a la empresa no fue una tarea difícil, consiguiendo entrar luego de dos semanas de su postulación, para lo cual solo tenía que garantizar la vigencia de su seguro, SOAT, acreditar sus antecedentes penales y presentar su brevete. Luego de ello, se hizo un nuevo colaborador de las entregas a domicilio.

Lleva laborando en la empresa aproximadamente cinco meses y hasta ahora se encuentra satisfecho con las condiciones en las que labora. Según él, los beneficios que obtiene son mejores que las que ofrecen otro trabajo. En especial la flexibilidad laboral, ya que es él mismo quien decide cuándo y cómo trabajar. Diariamente labora de unas ocho a diez horas, teniendo lapsos de tiempo en las que aprovecha para descansar. Estos lapsos se dan en horarios con poca demanda, generalmente entre las $3 \mathrm{pm}$ a $6 \mathrm{pm}$. Su día de trabajo inicia al medio día, coge el celular y empieza a buscar pedidos, por medio del GPS que manda una señal para que acepte el pedido e inicie el trayecto de recojo del pedido hasta la entrega de esta. Él llega a abarcar varios distritos en las que Uber Eats tiene cobertura, distritos como Miraflores, San Isidro, Barranco, San Miguel y Callao. Y el recorrido que hace, en kilómetros, marca el porcentaje de su ganancia, siendo unos dos soles (S/. 2.00) el monto por kilómetro. En un buen día llega a ganar unos doscientos soles (S/. 200.00), mientras que, en un mal día, no baja de los ochenta soles (S/. 80.00). Siendo su ingreso mensual unos tres mil seiscientos soles (S/. 3 600.00).

Comenta que la relación que guarda con la empresa es débil y solo son monitoreados para prevenir cualquier inconveniente durante la entrega del pedido. Reconoce que está expuesto a los peligros que representa transportarse en moto, tanto la delincuencia o la imprudencia lo ponen en peligro. Juan, evidencia que este tipo de empresas ha significado un campo laboral con gran aceptación de migrantes venezolanos, que debido a los pocos requisitos que piden, permiten que sea más accesible el ingreso de ellos y ellas como nuevos colaboradores.

\section{Análisis de resultados}

A partir de estas entrevistas se pueden señalar algunas características principales propias de este trabajo y que han sido mencionadas teóricamente en los párrafos anteriores. Los tres repartidores coinciden en señalar que estas empresas por aplicativo representan una alternativa innovadora que les permite obtener mayores ingresos y mejorar las condiciones socioeconómicas en la que viven. Esto se refuerza con la idea de flexibilidad laboral, autonomía e independencia en el trabajo, ideas que se expresan en la supuesta liberad 
que tiene el repartidor al momento de elegir los horarios para hacer los repartos, elegir cuando descansar y hasta decidir cuánto se quiere ganar. Sin embargo, todos ellos reconocen a su vez que esta forma de trabajo se relaciona con un tipo de trabajo informal, ya que no están inscritos en una planilla y no tienen un contrato firmado, por lo que están exceptos de seguros u otros beneficios. Pese a ello, ellos se sienten que los beneficios que tienen hoy son suficientes como para poder lidiar con las dificultades propias de la ausencia de relación contractual.

En ese sentido, podemos señalar algunas contradicciones en el discurso que promueve estas economías colaborativas. En primer lugar, si bien existe una libertad en la elección de los horarios, ya sea mañana, tarde o noche, estos horarios elegidos no estarán fuera de las horas con mayor demanda. Es decir, los repartidores se verán inducidos a elegir un horario con mayor movimiento con el fin de ganar más. Esta libertad en la elección del horario, además, dependerá también del récord que estos repartidores tengan en el proceso de reparto, el cual será definido por la calificación hecha por los usuarios a estos repartidores, sobre las actitudes, el trato, el tiempo de entrega y otras razones a nivel subjetivo. Este rango de calificación es administrado por la empresa y es a partir de estas calificaciones, que diseñan toda una estrategia de recompensa, se flexibiliza la capacidad de elección para aquellos repartidores con mejores calificaciones y se restringe el acceso a horarios con mayor movimiento a quienes no hayan alcanzado las expectativas de la empresa.

En segundo lugar, con respecto a la libertad para decidir cuándo hacer los repartos, es contradictoria también, ya que esa supuesta libertad está condicionada por la necesidad de obtener mayores ganancias. En ese sentido se entiende que los repartidores optarán por captar más pedidos y en horarios más largos con el fin de tener mayores ganancias y aliviar las necesidades que lo llevaron a laborar en esas condiciones.

En tercer lugar, la autonomía que rige este tipo de trabajo, la cual promueve y defiende la idea de independencia, el ser "tu propio jefe», también recae en una contradicción, puesto que, y debido a las razones expuestas arriba, el servicio que presta el repartidor no se hace a su propia voluntad, sino que se rige por ciertas instrucciones de la empresa y por sus condiciones fijadas al colaborador al momento de ingresar a la empresa. El hecho de tener que valerse de un aplicativo, descargarlo en un teléfono móvil adecuado y de alta gama, (para que soporte el aplicativo), recibir instrucciones cada cierto tiempo sobre cómo realizar las entregas o cómo gestionar algún problema que se presente desde el soporte técnico, el cumplir un tiempo adecuado para la entrega, vestir de manera "adecuada», estar presentable, estar monitoreado por un GPS; evidencian claras características que este tipo de trabajo dentro de las economías colaborativas, no son de tipo autónomo ni independiente, sino que por el contrario, es un tipo de trabajo que depende de la empresa para realizar el trabajo. Y más bien, estas empresas se valen de esa falsa autonomía para eludir deberes y derechos que están contemplados 
en las relaciones laborales y formales. Deberes como el pago de un seguro, pago de indemnizaciones en caso de accidentes, ya que como se ha evidenciado en las entrevistas, los colaboradores están propensos a sufrir accidentes. Debemos añadir, que a estas primeras observaciones que se hacen a este tipo de economía, se le suma una característica importante y que es promovida por el sistema neoliberal dentro de una economía de mercado global, nos referimos al fenómeno de individualización del sujeto, con lo que se promueve la idea de independencia y que las esperanzas de progreso y desarrollo descansan solo en la persona de manera aislada, y que sus condiciones no dependen de lo social o de las problemáticas que suceden a nivel general.

En líneas generales, podemos señalar que esta forma de economía colaborativa, como consecuencia de las dinámicas capitalistas, busca negar las relaciones laborales, negando las condiciones de sus colaboradores como trabajadores y trabajadoras, con el fin de reducir responsabilidades, generar mayores ganancias en perjuicio de la población que se vale de estas empresas para mejorar su nivel de vida. Sin embargo, estos tipos de economías colaborativas acrecientan las condiciones de precarización y recrudecen la explotación laboral. Al poner toda la carga laboral y de ingresos al esfuerzo de cada trabajador. Lo que se genera es la negación de los derechos logrados históricamente por los trabajadores de todas partes del mundo.

Las distintas entrevistas hechas coinciden en mostrar, en un primer momento, que estas nuevas formas laborales, son una oportunidad de crecimiento económico y que te permite gozar de beneficios, como el «ser tu propio jefe o jefa», algo que la economía tradicional, es decir, el mercado laboral tradicional, restringe este goce para solo unos pocos. Parece que el discurso de la autonomía laboral está empezando a ganar adeptos en el país, y cada vez son más las nuevas subjetividades que se construyen alrededor de un emprendedurismo falso, el cual se debe también al incipiente desarrollo que estas empresas están teniendo en el país, quizá, con un poco más de tiempo, se escuchen voces de reclamo y rechazo, desde la población, hacia estas nuevas formas de precariedad laboral.

Como ya se ha afirmado anteriormente, estas economías colaborativas suponen la transformación de la figura tradicional del consumidor, en un emprendedor, lo que implica que el trabajador que se hace repartidor sea no solo beneficiario total de lo que logre obtener, sino que tenga que asumir con todas las responsabilidades, los pasivos, que implica el trabajo. Los testimonios lo muestran, que, ante la ineficiencia de estas empresas, de sus soportes técnicos o centrales de atención, son ellos o ellas mismas que tienen que resolver las dificultades que se van presentando, y esto es algo que prefieren hacer y no lo ven mal, es más, consideran que la experiencia obtenida antes, les permite asumir mejor este nuevo trabajo. 


\section{Conclusiones}

Desde la década del 90 se produjo la expansión y la hegemonía del discurso neoliberal, el cual lo podemos apreciar con mayor nitidez en el discurso del emprendedor, que reduce lo político y anula lo colectivo, para dar paso al pragmatismo y al proyecto individualista de autogerenciarse desde los emprendimientos que emergen como nuevas formas laborales precarizadas.

En este contexto histórico surgen estas economías colaborativas que se presentan también como una innovación disruptiva, que implica que el triunfo de este nuevo modelo, que no solo depende de los propias empresas ni de los repartidores, sino de un conjunto de fuerzas en donde interviene inclusive el propio Estado, con sus omisiones en las políticas y falta de atención a las problemáticas sociales y que generan las condiciones para que la población busque otras opciones para mejorar su situación, así también interviene la propia estructura socioeconómica, el cual sigue un patrón económico de sistema mundo y un modelo neoliberal. En este contexto, es que se fortalece la desigualdad social y económica, esta economía colaborativa se construyen como parte de un mercado desigual, que reproduce esas desigualdades sociales y las profundiza. Todas las ventajas que han sido presentadas en este trabajo, como muestra teórica y como testimonio real de los repartidores, no están dispuestas libremente para todos, aunque así parezca, estos beneficios van a depender de las condiciones socioeconómicas de las personas, de los bienes que posee y de las aptitudes que ha desarrollado.

Vale decir, una persona con un mayor capital económico interviene en estas economías colaborativas como una forma de aumentar lo que ya tiene, mas no como una forma de encontrar ese ingreso mínimo que necesita para vivir. Mientras que aquellos propios de las clases medias, no les implica mayores costos, esta nueva economía se le presenta como una forma de encontrar un ingreso extra. En cambio, las persona en condiciones más precarias, quienes no cuentan con capitales, la economía colaborativa se le presenta como una trampa, estas son personas que el mercado tradicional ya no los pueden aceptar o si es que siguen laborando, sus ingresos son menores que el mínimo, y no les asegura el poder sobrevivir.

Asimismo, esta nueva economía colaborativa afín del discurso del emprendedurismo fragmenta aún más la estructura social y debilita los lazos de confianza necesarios para la cohesión social. Enfatizan el sentido de la independencia, es por ello, que estas nuevas formas laborales han sabido ganarse una amplia aceptación acerca de que la autonomía laboral es mejor y te permite concentrar las mejores ganancias, de esta forma se afirma el individualismo, y se vuelve innecesario establecer contacto con el otro, pues ello representa una "pérdida de tiempo».

En conclusión, este nuevo trabajador ya no posee más el control de su tiempo ni de su espacio de descanso, ha sido despojado de estos últimos reductos de la vida personal 
y ha sido arrojado a esta nueva dinámica esquizofrénica del mercado, la mercantilización del sujeto y de su tiempo.

Ahora está sujeto a las constantes exigencias y demandas del trabajo, y movido por el miedo ante la posibilidad de perder el empleo, el trabajador precarizado ya no puede construir un proyecto de vida, la inmediatez y la inseguridad son los signos distintivos del trabajador actual. Se produce de esta forma, la fragmentación de las relaciones sociales y la imposibilidad de cualquier forma de organización comunitaria y participación política, debilitando más nuestra precaria democracia, la misma que se encuentra erosionada por la expansión de la inseguridad social en el país.

\section{Referencias}

Bauman, Z, (2004). La Modernidad liquida. Buenos Aires: Fondo de Cultura Económica Beck, Ulrich (2013). La sociedad del riesgo: hacia una nueva modernidad. Barcelona: Paidós

BID (2016). Economía Colaborativa en América Latina. Descargado el 02 de febrero. https://publications.iadb.org/es/publications/spanish/document/Econom\%C3\%ADa-colaborativaen-Am\%C3\%A9rica-Latina.pdf

Boltanski, Luc; Chiapello, Ève (2002). El nuevo espiritu del capitalismo. Madrid: Akal.

Buenadicha, C., Cañigueral Bagó, A., \& De León, I. L. (2017). Retos y posiblidades de la Economía Colaborativa en América Latina y el Caribe. Banco Interamericano de Desarrollo Bourdieu, Pierre (1999). En la actualidad, la precarie-dad está en todas partes. En: P. Bourdieu, Con-trafuegos. Reflexiones para servir a la resisten-cia contra la invasión neoliberal (pp. 120-128). Barcelona: Anagrama

Castel, R. (2012). El ascenso de las incertidumbres. Trabajo, protecciones, estatuto del individuo. Fondo de Cultura Económica, Buenos Aires

Castel, R. (2004). La inseguridad social ¿Qué es estar protegido? Buenos Aires. Manantial

De la Garza, E. (2000). La flexibilidad del trabajo en América Latina. En E. de la Garza, Tratado latinoamericano de sociología del trabajo. México: Fondo de Cultura Económica.

Dombois R. (1995). ¿Necesita América Latina su propia sociología del trabajo? Revista latinoamericana de Estudios del Trabajo, 1(1), 97-132.

Forrester, V. (2010). El horror económico. México: Fondo Cultura Económica (FCE)

Gil García, J. (2017). Desigualdades, límites y posibilidades para la transformación del capital en las economías colaborativas. Redes.com, 33 - 67.

Gordo López, A., De Rivera, J., \& Cassidy, P. (2017). La economía colaborativva y sus impactos sociales en la era del capitalismo digital. En R. Coratelo, \& J. Gil, Ciberpolitica:gobierno abierto, redes, deliberación, democracia. (págs. 189 - 208).

Hípola, R. (2017). Diseño de una metodología de análisis de las plataformas digitales y sus modelos de negocio en el ecosistema digital. 
Inga (2018). Uber Eats ingresa al Perú de la mano de 300 restaurantes, El Comercio: Recuperado de https:/elcomercio.pe/economia/peru/ uber-eats-ingresa-peru-mano-300-restaurantes-noticia- 518165.

Kalamar, A. (2013) Sharewashing is the new greenwashing. Recuperado de https:/www. opednews.com/populum/page.php?f=Sharewashing-is-the-New-Gr-by-Anthony-Kalamar-130513-834.html

Largacha, M. C. \& Tatis, G. (2017). BIG DATA, la solución para las plataformas de domicilios. Recuperado de: http://hdl.handle.net/10726/1687

Moruno, J. (2015). La fábrica del emprendedor. Trabajo y política en la empresa mundo. Madrid: Akal.

Moruno, J. (2018). No tengo tiempo. Geografias de la precariedad. Madrid: Akal.

Navarro, V. (2002). Bienestar insuficiente, democracia incompleta. Barcelona: Anagrama.

Navarro, V. (2015). Ataque a la democracia y al bienestar. Crítica al pensamiento económico dominante. Barcelona: Anagrama.

Perez (2016). Rappi, plataforma que busca facilitar todo a las personas. En portal Siliconweek: https://www.siliconweek.com/e-enterprise/ rappi-plataforma-que-busca-facilitar-todo-a-las-personas-72314?print=pdf.

Pikketty, T. (2014). El capital del siglo XXI. México: Fondo Cultura Económica.

Rodríguez, J. ed. (2010). Desafíos laborales en América Latina después de dos décadas de reformas estructurales, Bolivia, Paraguay y Perú (1997-2008). Lima: Fondo editorial de la Pontificia Universidad Católica del Perú; IEP.

Sagardoy, I., \& Núñez Cortés, P. (2017). Economía colaborativa y relación laboral: ¿un binomio conflictivo? Cuadernos, de pensamiento político., 93 - 101.

Sánchez R. (2013). Enfoques, conceptos y metodologías de medición de la informalidad laboral en Colombia. Lecturas de Economía, 79, 9-43.

Sassen, S. (s/f). Expulsiones Brutalidad y complejidad en la economía global. Buenos Aires: Katz.

Standing, G. (2013). El precariado. Una nueva clase social. Barcelona: Pasado y Presente.

Standing, G. (2014). Por qué el precariado no es un «concepto espurio». En revista Sociología del Trabajo. No 82 Nueva Época. Editores Siglo XXI.

Standing, G. (2017). La corrupción del capitalismo. Por qué prosperan los rentistas y el trabajo no sale a cuenta. Barcelona: Pasado y Presente.

Stiglitz J. (2015). El precio de la desigualdad. Madrid: Editorial Debolsillo.

Vallefin, L. A. (2018). ¿Inflando el «Glovo»?: un análisis sobre los nuevos mecanismos de delivery y su abordaje en la jurisprudencia reciente. Derechos en acción, 403-426. 